\title{
Synthone Chemistry. Theoretical Study on the Formation of Valine, Leucine, Isoleucine and Methionine
}

\author{
GHEORGHE SURPATEANU1 ${ }^{1}$, ANA-MARIA GEORGESCU²*, ILEANA-DENISA NISTOR ${ }^{2}$, \\ NECULAI CATALIN LUNGU ${ }^{3}$ \\ ${ }^{1}$ Academy of Romanian Scientists (ARS), 54 Splaiul Independetei, 050094, Bucharest, Romania \\ 2"Vasile Alecsandri" University of Bacău, Department of Chemical and Food Engineering, 157 Calea Marasesti, 600115, \\ Bacau, Romania \\ ${ }^{3}$ Al.I. Cuza University of Iasi, Faculty of Chemistry, Department of Organic Chemistry and Biochemistry, 11 Carol I Blvd., \\ 700506, Iasi, Romania
}

\begin{abstract}
According to synthonic theory of the formation of proteinogenic amino acids and of corresponding polypeptides, starting from three synthons (methylene, nitrene and carbon monoxide), four proteinogenic amino acids have been constructed: valine, leucine, isoleucine and methionine. This paper represents a theoretical, thermodynamic and reactivity study on the formation of the four previously mentioned amino acids at low temperatures. All the intermediates involved in the formation of these amino acids as well as the final products obtained by contact with water, an essential component of the Earth's primary atmosphere, are specified. Quantitative data, formation enthalpies, reaction enthalpies and free energies were obtained in principle by DTF (B88-LYP) calculations.
\end{abstract}

Keywords: amino acids, in silico (DFT), synthons, thermodynamics, aziridinone radicals

\section{Introduction}

According to the synthon theory [1-3] on the formation of proteinogenic amino acids and of corresponding polypeptides at low temperatures, aziridinone would have been formed from three synthons: methylene, nitrene and carbon monoxide. This one, in contact with these three synthons, somewhere outside the Earth's atmosphere, would form the precursor of radical structures. These, in contact with the components of the primary atmosphere, lead to proteinogenic amino acids and polypeptides.

Some of the proteinogenic amino acid precursors lead to polypeptide precursors, by copolymerization. The first polypeptides would have formed from polypeptide precursors and not from amino acids.

The structures of chemical sample were refined by performing an optimized geometry calculation in Mechanics using successively: augmented MM3 parameters, MOPAC AM1 parameters and DGauss with B88-LYP, GGA functional with the DZVP basis set [4, 5].

In previous works $[6,7]$, we have shown how the following proteinogenic amino acids can be obtained: glycine, alanine, serine, cysteine, aspartic acid, asparagine and threonine. In this paper we continue the construction of four further proteinogenic amino acids: valine, leucine, isoleucine and methionine. The choice of amino acid groups took into account the structural elements and the nature of the reactions involved in their construction. Among the many reactions that would form the aforementioned amino acids, we chose those "open shell" transformations, which involve radical intermediates and photochemical-radical reaction pathways. Specifically, in these transformations, we have a continuous decrease of the energies of the reaction systems in the transitions from the initial products to the final reaction products.

\footnotetext{
*email: ana.georgescu@ub.ro 


\section{Computational details}

The structure corresponding to the reaction path, with all kinetic energy removed at every step, are calculated in DGauss using the B88-LYP GGA functional with the DZVP sets. This calculation requires the input file by a transition state geometry $[8,9]$.

The transition state structure of the chemical sample is refined by performing a transition state calculation using B88-PW91 GGA energy functional with the DZVP basis sets.

The computational part used is the Cache Work System Library, version 7.5.0.85 [10].

\section{Results and discussions}

According to a general schema (schema 1), the three synthons (S) form aziridinone.

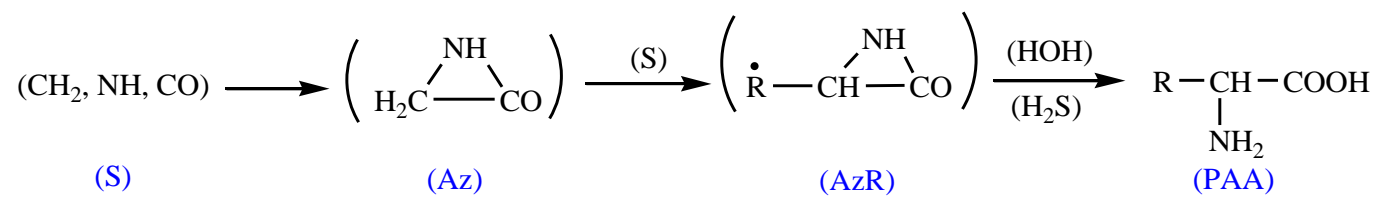

Schema 1. Formation of proteinogenic amino acids

This, in contact with methylene, leads to aziridinone radicals intermediates AzR, precursors of valine, leucine, isoleucine and methionine. These intermediates upon contact with water are forming the four proteinogenic amino acids mentioned above.

\subsection{Thermodynamics calculated data}

The enthalpies of formation of all the radical intermediates and of neutral molecules, reactants or final reaction products were calculated first. In previous works [6, 7], quantitative data on C-methylaziridinonyl radical 11 (table 1) were presented in detail. Shortly, it would be obtained from the Caziridinonyl radical and methylene. The C-methyl-aziridinonyl radical is intermediate, a starting point for all four proteinogenic amino acids studied in this work.

Table 1. Enthalpies of formation. Radicals and neutral molecules.

\begin{tabular}{|c|c|c|c|}
\hline No & Compound & Multiplicity & $\begin{array}{c}\text { Enthalpies of formation, } \Delta H \\
\text { (a.u.)* }\end{array}$ \\
\hline 1 & $\mathrm{HOH}$ & 1 & -76.422235 \\
\hline 2 & $\mathrm{H}_{2} \mathrm{~S}$ & 1 & -399.34186 \\
\hline 3 & $\mathrm{CH}_{3}-\mathrm{S}-\mathrm{H}$ & 1 & -438.63607 \\
\hline 4 & $\mathrm{H}_{3} \mathrm{C}-\mathrm{S}-\mathrm{H}_{2} \mathrm{C}-\mathrm{H}_{2} \mathrm{C}-\stackrel{\mathrm{NH}}{\mathrm{CH}}-\stackrel{\mathrm{CO}}{\mathrm{C}}$ & 1 & -723.95797 \\
\hline 5 & 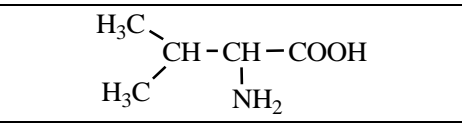 & 1 & -402.29791 \\
\hline 6 & 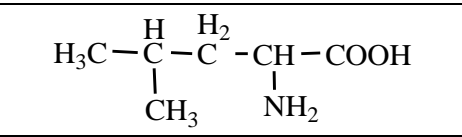 & 1 & -441.59382 \\
\hline 7 & $\begin{array}{c}\mathrm{H}_{2} \\
\mathrm{H}_{3} \mathrm{C}-\mathrm{C}-\mathrm{CH}-\mathrm{CH}-\mathrm{COOH} \\
\stackrel{\mathrm{I}}{\mathrm{C}} \mathrm{H}_{3} \mathrm{NH}_{2}\end{array}$ & 1 & -441.59352 \\
\hline 8 & $\begin{array}{c}\mathrm{H}_{3} \mathrm{C}-\mathrm{S}-\mathrm{H}_{2} \mathrm{C}-\mathrm{H}_{2} \mathrm{C}-\stackrel{\mathrm{H}}{\mathrm{C}}-\mathrm{COOH} \\
\stackrel{1}{\mathrm{NH}_{2}}\end{array}$ & 1 & -800.44850 \\
\hline 9 & $\mathrm{CH}_{2}$ & $\begin{array}{l}1 \\
3 \\
\end{array}$ & $\begin{array}{l}-39.11805 \\
-39.13454 \\
\end{array}$ \\
\hline 10 & $\dot{\mathrm{C}} \mathrm{H}_{3}$ & 2 & -39.81778 \\
\hline
\end{tabular}




\begin{tabular}{|c|c|c|c|}
\hline 11 & 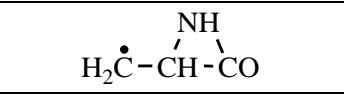 & 2 & -246.56109 \\
\hline 12 & 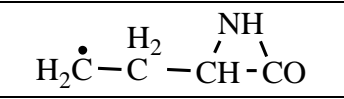 & 2 & -285.84935 \\
\hline 13 & 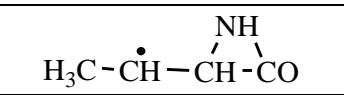 & 2 & -285.89121 \\
\hline 14 & 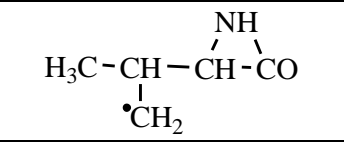 & 2 & -325.14435 \\
\hline 15 & 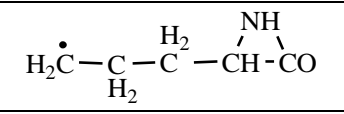 & 2 & -325.14359 \\
\hline 16 & 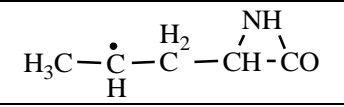 & 2 & -325.14925 \\
\hline 17 & 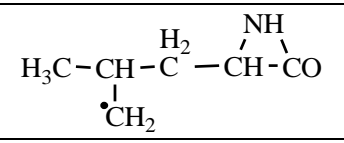 & 2 & -364.43847 \\
\hline 18 & 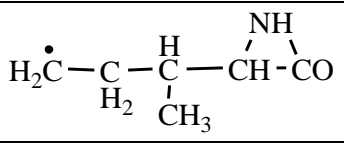 & 2 & -364.43866 \\
\hline
\end{tabular}

*a.u. = atomic units (hartrees); atomic unit $=2625 \mathrm{~kJ} / \mathrm{mol}$

Next, in table 2, all the chemical transformations that result from the aforementioned amino acids, are specified. In the last column of the table the values of the reaction enthalpies $\Delta H_{r}$ are given. They confirm that all transformations are exothermic. In this way, a first step towards the compliance of the reaction model imposed and announced in the introduction of this paper is respected.

We mention that there are several reaction steps regarding the formation of these four amino acids which are repeated from one case to another.

As for methionine, its formation is perhaps more difficult to explain. We assume that the C-methylaziridinonyl radical would react with methyl-thiol, a sulfur-containing compound. Under these conditions, it is assumed that the amino acid precursor intermediates are accompanied by synthons and carried by nitrogen until contact with the components of the primary atmosphere. The latter should also contain hydrogen sulphide, as previously suggested [11]. Under these conditions, the formation of $\mathrm{CH}_{3} \mathrm{SH}$ would become a natural thing. Thus, $\mathrm{CH}_{3}, \mathrm{CH}_{3} \mathrm{~S}$ and $\mathrm{H}_{2} \mathrm{~S}$ are on the list of interstellar molecules [12].

Table 2. Reaction enthalpies $\left(\Delta H_{\mathrm{r}}\right)$. Formation of valine, leucine, isoleucine and methionine.

\begin{tabular}{|c|c|c|c|c|}
\hline No & Amino acid & Reactions & $I_{d}$ & $\begin{array}{c}\Delta H_{r} \\
(\mathrm{kcal} / \mathrm{mol})\end{array}$ \\
\hline \multirow[t]{2}{*}{1} & Valine & 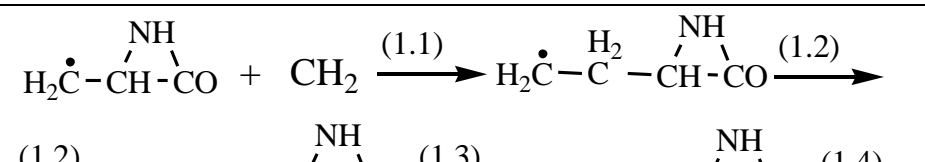 & $\begin{array}{l}1.1 \\
1.2 \\
1.3 \\
1.4\end{array}$ & $\begin{array}{l}-96.47 \\
-26.26 \\
-74.42 \\
-458.83\end{array}$ \\
\hline & & 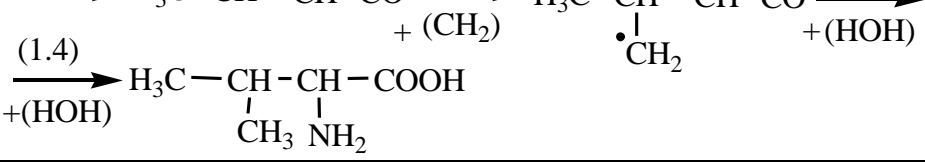 & & \\
\hline
\end{tabular}




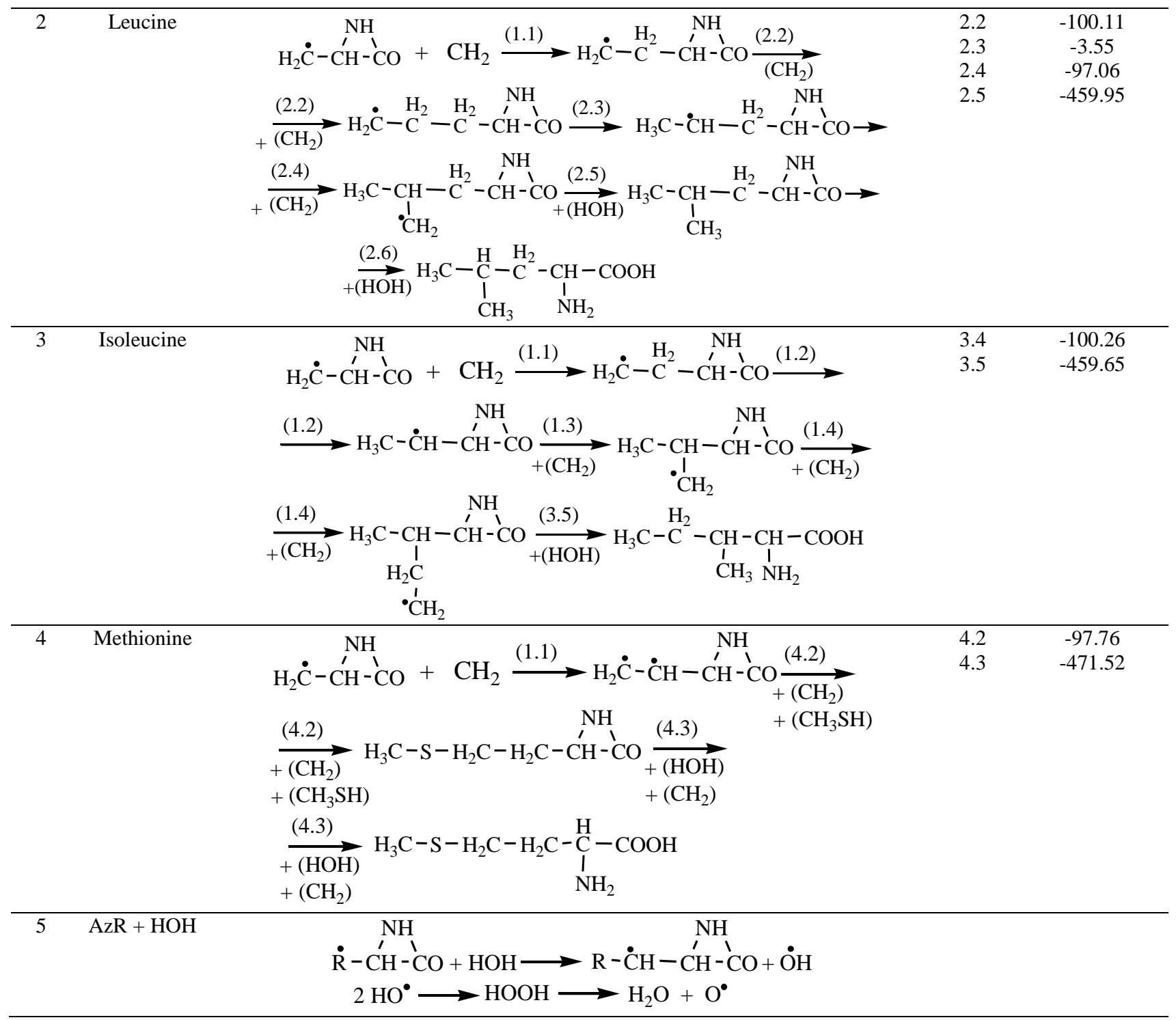

Hydrogen cannot be evaluated as a distinct chemical entity. This is why in reaction 4.3 we included a hydrogen fixing agent. This would be methylene, in triplet ground state.

\subsection{Reaction pathways}

Table 3 shows the values of the enthalpies of formation $\Delta H_{i}$ and $\Delta H_{f}$. These refer to the initial and final states involved in the reactions indicated by $I_{d}$ values and suggested by figure 1.a. The last column of this table gives the values of Gibbs free energies, $\Delta G$. All the reactions presented show reaction pathways that involve a continuous decrease of the energies in the passage from the initial products to the final ones.

Table 3. Enthalpies $\left(\Delta H_{i}, \Delta H_{f}\right)$ and free energies $(\Delta G)$.

Formation of valine, leucine, isoleucine and methionine

\begin{tabular}{|c|c|c|c|c|}
\hline No & $I_{d}$ & $\Delta H_{i}$ (a.u.) & $\Delta H_{f}$ (a.u.) & $\Delta G(200 / 300$ K) (a.u.) \\
\hline 1 & 1.1 & -285.69562 & -285.84935 & -285.777481 \\
\hline 2 & 1.2 & -285.84935 & -285.89121 & 285.788200 \\
\hline 3 & 1.3 & -325.02574 & -325.14435 & $\begin{array}{l}-285.777665 \\
-385.788389\end{array}$ \\
\hline 4 & 1.4 & -401.56670 & -402.29791 & $\begin{array}{l}-325.046188 \\
-325.057293\end{array}$ \\
\hline 5 & 2.2 & -324.98389 & -325.14359 & - \\
\hline
\end{tabular}




\begin{tabular}{ccccc}
\hline 6 & 2.3 & -325.14359 & -325.14925 & -325.045035 \\
\hline 7 & 2.4 & -364.28378 & -364.43847 & -325.056022 \\
\hline \multirow{2}{*}{8} & 2.5 & -440.86082 & -441.59382 & -325.050577 \\
& & & -364.43866 & -364.312755 \\
\multirow{2}{*}{9} & \multirow{2}{*}{3.4} & -364.27888 & -364.324222 \\
\hline 10 & 3.5 & -440.08622 & -441.59352 & - \\
\hline 11 & 4.2 & -763.61995 & -763.77575 & - \\
\hline 12 & 4.3 & -839.51485 & -840.26628 & - \\
\hline
\end{tabular}

In Figure 1.b, the reaction between the C-methyl-aziridinonyl radical and the methylene triplet is given as a model.

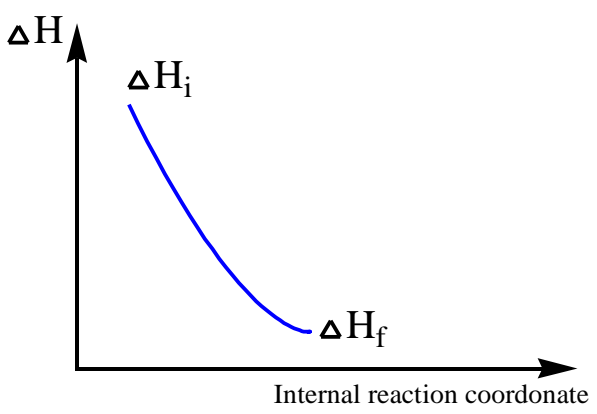

(a)

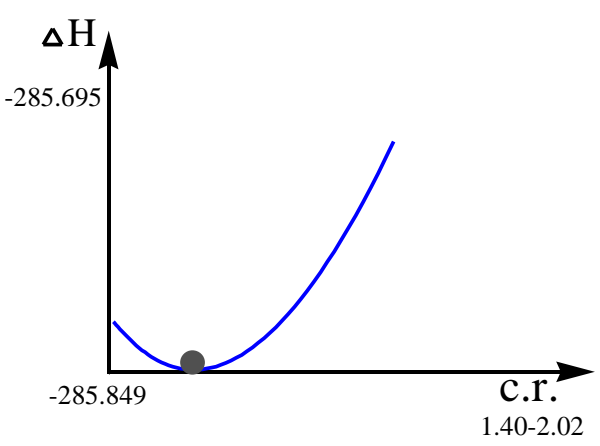

(b)

Figure 1. General allure of all reaction pathways (a); the reaction between the C-methyl-aziridinonyl radical and the methylene triplet (b).

The reactions that would take place between the intermediates and the two components belonging to the Earth's primary atmosphere, water and hydrogen sulfide, have not been studied.

The activation energies that these reactions would need, can be reached, given the higher temperature that would have existed at the contact of radical intermediates - atmospheric components. Reactions between AzR radicals and water (reaction 5 in table 2) would lead to the occurrence of oxygen in water, which is particularly spectacular $[13,14]$.

\section{Conclusions}

Several conclusions can be highlighted:

- All the precursor intermediates of valine, leucine, isoleucine and methionine were constructed, starting from the C-methyl-aziridinonyl radical;

- All the transformations suggested in the formation of the four amino acids are exothermic;

- The study of chemical reactivity shows reaction pathways with continuous decreasing of the energies of the molecular systems involved, on the way from the initial states to the final states;

- Methionine would be obtained in a slightly more complicated way, by involving radical reactions by means of hydrogen sulphide $\left(\mathrm{H}_{2} \mathrm{~S}\right)$;

- It is suggested the formation of molecular oxygen in water upon its contact with the precursor radical intermediates.

This research did not receive any specific grant from funding agencies in the public, commercial, or not-for-profit sectors.

\section{References}

1. SURPATEANU, G., Syntone chemistry and prebiotic stage in life evolution 1. Aziridinone, a key compound in formation of the first proteinogenic amino acids and polypeptides, Int. J. Astrobiology, 17(4), 2018, 361-379.

2. SURPATEANU, G., GHEORGHIȚĂ G., Synthone Chemistry and Prebiotic Stage, LAP, Lambert 
academic Publishing, ISBN 978-620-0-11527-0, 2019.

3. GHEORGHITA G., SURPATEANU, G., The prebiotic stage and the evolution of life on Earth, Environ. Nat. Resour. J., 9(2), 2019, 86-107.

4. STEWART, J. J. P., Optimization of Parameters for Semi-Empirical Methods I-Method. J. Comp. Chem., 10, 1989, 209-220.

5. DEWAR, M. J. S., HEALY, E. F., STEWART, J. J. P., Location of Transition States in Reaction Mechanisms, J. Chem. Soc., Faraday Trans. II, 80(3), 1984, 227-233.

6. SURPATEANU, G., NISTOR, I.D., GEORGESCU, A.M., LUNGU, N.C., Syntone chemistry. Theoretical study on the formation of glycine, alanine and serine, Rev. Chim., 70(5), 2019, 1707-1711.

7. SURPATEANU, G., NISTOR, I.D., GEORGESCU, A.M., LUNGU, N.C., Syntone chemistry. Theoretical study on the formation of cysteine, aspartic acid, asparagine and threonine, Rev. Chim., 2020 (submitted, manuscript ID 20.0051).

8. PARR, R.G., YANG, W., Density-functional theory of atoms and molecules, Oxford University Press, New York, 1989.

9. SALAHUB, D.R., in Ab initio Methods in Quantum Methods in Quantum Chemistry-II, Ed. Lawly, K.P., Wiley \& Sons, New York, 1987, 447.

10. Cache Worksystem Library, version 7.5.0.85, 2006, Fujitsu, Poland.

11. ZAHNLE, K.J., KASTING, J.F., POLLACK, J.B., Evolution of a steam atmosphere during Earth's accreation, Icarus, 74, 1988, 62-97.

12. Liste d'espèces chimiques détectées dans le milieu interstellaire ou circumstellaire, Nature, $\mathbf{5 6 8}$ (7752), 18 avril 2019.

13. BUCHANAN, B. B., LUAN, S., Redox regulation in the chloroplast thylakoid lumen: A new frontier in photosynthesis research, J. Exp. Bot., 56, 2005, 1439-1447.

14. FOYER, C. H., Reactive oxygen species, oxidative signaling and the regulation of photosynthesis, Environ Exp. Bot., 154, 2018, 134-142.

Manuscript received : 14.02 .2020 
